Info Artikel:

Diterima: 13/02/2018

\title{
Hubungan kontrol diri dengan prestasi belajar siswa
}

\author{
Citra Putri Intani ${ }^{1}$, Ifdil Ifdil ${ }^{2}$ \\ ${ }^{123}$ Universitas Negeri Padang
}

\begin{abstract}
Student achievement is found apda initial survey is still much under KKM while individuals who have high selfcontrol can direct and manage his behavior, not easily tempted by changes that occur and can avoid the deviant behavior, This study aims to analyze the relationship control self with student achievement with the strength of the relationship is quite strong in students at SMA Negeri 7 Padang. This type of research is quantitative research with the type of research is descriptive correlational research. The population of this study class XI and class XII SMA Negeri 7 Padang 2017/2018 as many as 596 students and a sample of 240 students. Sampling using simple random sampling technique. Instrument used for research in the form of closed questionnaire to know the relationship of self control with student achievement by using correlation test. The results revealed: 1) students' overall self-control was in the moderate category with the percentage of $38.8 \%$ 2) the overall student learning achievement $(26.7 \%)$ with the learning achievement score 62-67, and there was a significant relationship between self-control with learning achievement at SMA Negeri 7 Padang.
\end{abstract}

Keywords: self control, learning achievement

This is an open access article distributed under the Creative Commons Attribution License, which permits unrestricted use,
distribution, and reproduction in any medium, provided the original work is properly cited. (C) 2017 by author.

\section{PENDAHULUAN}

Pendidikan merupakan bagian terpenting dalam aspek kehidupan sebagai bekal dalam rangka membentuk mansuia yang cerdas dan berkualitas. Sesuai dengan undang-undang Sistem Pendidikan Nasional Republik Indonesia No. 2 tahun 2003 Bab II Pasal 3 yaitu pendidikan nasional bertujuan untuk berkembangnya potensi peserta didik agar menjadi manusia yang beriman dan bertaqwa kepada Tuhan Yang Maha Esa, berakhlak mulia, sehat, berilmu, cakap, kreatif, mandiri, dan menjadi warga negara yang demokratis serta bertanggung jawab.

Syah (2011: 141) menjelaskan prestasi belajar adalah keberhasilan siswa mencapai tujuan yang telah ditentukan sesuai dengan program. Prestasi belajar yang di capai siswa adalah sesuai kriteria yang telah di tetapkan prestasi belajar ini digunakan untuk menilai hasil yang di peroleh oleh siswa. .

Suryabrata (2006: 297) menjelaskan prestasi adalah nilai perumusan terakhir yang dapat diberikaan oleh guru mengenai kemajuan/prestasi siswa selama masa tertentu. dari pendapat di atas dapat disimpulkan prestasi belajar adalah hasil usaha siswa yang dapat dicapai berupa penguasaan, pengetahuan, kemampuan, kebiasaan dan keterampilan serta sikap setelah mengikuti proses pembelajaran yang dapat dibuktikan dengan hasil tes.

Banyak dijumpai di dalam sekolah khususnya SMA, siswa yang sering bermasalah yang umum terjadi dalam sekolah adalah perkelahian, permusuhan, mencontek, saling ejekan dan nilai yang menurun serta stres akademik, perubahan tuntutan belajar dari masa sebelumnya juga menyebabkan munculnya gejala stress (Zola, Fadli, \& Ifdil, I., 2018; Wardi, R., \& Ifdil, I., 2016; Ifdil, 2018). Stress akademik tidak sepenuhnya bermakna negatif melainkan dapat bermakna positif dalam artian dapat sebagai tantangan untuk mengatasinya (Barseli, M. Ahmad, \& Ifdil, I., 2017). Kondisi ini antara lain disebabkan oleh tuntutan yang tinggi terhadap prestasi siswa 
dimana hal seperti itu akan berdampak buruk terhadap prestasi belajar siswa itu sendiri di sekolah (Barseli \& Ifdil. I, 2017). Masalah yang sering terajdi karena lemahnya kontrol diri siswa yang mana akan mengakibatkan siswa tersebut mudah tersinggung, kurang percaya diri dan sulit mengendalikan dirinya. Kepercayaan diri merupakan suatu keyakinan seseorang terhadap segala aspek yang ada pada dirinya dan diwujudkan dalam tingkah laku sehari-hari serta bagaimana individu mampu menilai diri sendiri dan lingkungannya secara positif (Ifdil, I., Denich, A. U., \& Ilyas, A; Fitri, E., Zola, N., \& Ifdil, I., 2018).

Ghufron \& Rini (2011: 21) menjelaskan kontrol diri sebagai kemampuan untuk menyusun, membimbing, mengatur dan mengarahkan bentuk perilaku yang dapat membawa ke arah kosenkuensu yang psoitif. Calhoun dan Acocella (dalam Andaryani: 2013) mendefiniskan kontrol diri sebagai pengaturan proses-proses fisik, psikologis, dan perilaku seseorang, dengan kata laian serangkaian proses yang membutuhkan dirinya sendiri.

Chaplin (2011: 43) menjelaskan kontrol diri adalah kemampuan untuk membimbing tingkah laku sendiri, kemampuan untuk menekan atau merintangi impuls-impuls atau tingkah laku impulsif. jadi, kontrol diri merupakan suatu pengendalian tingkah laku seseorang yang cenderung bertindak positif dalam berfikir. Salah satu perilaku negatif yang mungkin terjadi apabila siswa memiliki kontrol diri yang rendah adalah perilaku bolos ketika jam pelajaran. Kontrol diri dapat diartikan ssebagai perasaan bahwa seseorang dapat membuat keputusan dan mengambil tindakan yang efektif untuk menghasilkan sesuatu yang diinginkan.

Berdasarkan penenlitian Arum (2015) menunjukkan bahwa terdapat hubungan yang positif signifikan antara kontrol diri dengan prestasi belajar siswa. Lemahnya kontrol diri siswa dapat dilihat dari hasil penelitian Astria (2014), terdapat 25,06\% siswa memilki kontrol diri sedang dan 15,93\% siswa memiliki kontrol diri rendah, Kemudian penelitian dari Elani (2015), kontrol diri siswa berada pada kategori rendah 39,1\% dang sangat rendah $13,8 \%$. Keinginan setiap individu yang ditunjukan melalui prestasi-prestasi yang di perolehnya. Kesuksesan bagi seorang siswa apabila mampu menunjukkan prestasi melalui hasil belajar yang baik dan mencapai kriteria ketuntasan minimal (KKM) serta jauh dari terutama akademik (Reski, N., Taufik \& Ifdil, 2013).

Berdasarkan dari temuan penelitian dapat disimpulkan hubungan kontrol diri siswa dengan prestasi belajar terdapat hubungan yang cukup kuat. Kenyataan yang ditemukan di SMA Negeri 7 Padang, ada beberapa siswa yang tidak bisa mengontrol dirinya sehingga mengakibatkan rendahnya prestasi belajar siswa tersebut. Keinginan setiap individu yang ditunjukan melalui prestasi-prestasi yang di perolehnya. Kesuksesan bagi seorang siswa apabila mampu menunjukkan prestasi melalui hasil belajar yang baik dan mencapai kriteria ketuntasan minimal (KKM) serta jauh dari terutama akademik (Reski, N., Taufik \& Ifdil, 2013).

Informasi lebih lanjut juga diperoleh dari wakil kepala sekolah SMA Negeri 7 Padang pada bulan Juni 2017/2018 sewaktu melaksanakan PLBK-S menjelaskan bahwa SMA Negeri 7 Padang sekolah yang melaksananakan kurikulum K13. Upaya yang dilakukan untuk membantu siswa agar memperoleh prestasi belajar yang optimal dilakukan oleh siswa dan semua personil yang ada di sekolah termasuk guru bimbingan dan konseling, dari 5 orang guru bimbingan dan konseling di sekolah kelimanya memiliki perahtian yang perlu di sekolah dalam upaya peningjkatan prestasi belajar siswa.

Untuk membantu kontrol diri yang baik pada siswa, diperlukan bimbingan dan konseling. Bimbingan dan konseling merupakan salah satu cara yang bisa dilakukan untuk memberikan jasa, manfaaat atau kegunaan tertentu dalam mencari pemecehan ataupun mencegah terjadinya masalah pada diri individu (Prayitno, 2004: 24).

Menurut Miftakhul (2017) Peran BK dalam kontrol diri siswa adalah membantu siswa dalam mengontrol sikap serta perilaku dan pengendalian diri yang baik yaitu dengan melakukan pendekatan kepada siswa agar siswa merasa nyaman serta terbuka kepada konselor guru BK dan mencari sumber permasalahan yang dihadapi siswa. Serta memberikan layanan informasi dan layanan penguasaan konten di kelas dengan memberikan nasehat dan motivasi kepada siswa. untuk itu disamping orangtua, konselor di sekolah juga mempunyai peranan penting dalam membantu mengatasi kesulitannya, keterbukaan hati konselor dalam membantu kesulitan remaja, akan menjadikan remaja sadar akan sikap dan tingkah lakunya yang kurang baik yang dimiliki. Pada periode perkembangannya remaja dituntut untuk menguasai salah satu tugas perkembangan yaitu perkembangan sosial untuk bersosialisasi dengan keluarga dan lingkungan sekitarnya dan juga menyesuiakan diri dengan norma yang berlaku dimasyarakat. 
Tujuan yang hendak dicapi pada penelitian ini adalah mengidentifikasikan: 1) mengidentifikasikan kontrol diri siswa SMA Negeri 7 padang, 2) mengidentifikasikan prestasi belajar siswa SMA Negeri 7 Padang, 3) mengidentifikasikan hubungan kontrol dir dengan prestasi belajar siswa SMA Negeri 7 Padang.

\section{METODOLOGI}

Penelitian ini menggunakan metode kuantitatif dengan pendekatan analisis korelasional yang bertujuan untuk mengetahui seberapa besar kontribusi antar variabel penelitian. Variabel penelitian ini terdiri dari kontrol diri (X) merupakan variabel bebas dan prestasi belajar (Y) merupakan variabel terikat. Dengan demikian, penelitian ini mengungkapkan hubungan kontrol diri dengan prestasi belajar siswa SMA Negeri 7 Padang, dengan jumlah sampel 240 orang. Instrumen penelitian yang digunakan adalah kuesioner medel skala likert. Data yang diperoleh dianalisis dengan menggunakan teknik persentase.

\section{HASIL}

Berdasarkan hasil pengolahan data yang telah dilakukan, hasil penelitian disajikan sesuai dengan tujuan penelitian yang diajukan sebelumnya, yaitu mengidentifikasikan: 1) mengidentifikasi kontrol diri siswa SMA Negeri 7 Padang, 2) mengidentifikasi prestasi belajar siswa SMA Negeri 7 Padang, 3) mengidentifkasi hubungan antara kontrol diri dengan prestasi belajar siswa SMA Negeri 7 Padang.

\section{Kondisi Kontrol Diri secara Umum}

Berdasarkan hasil penelitian yang dilakukan, kontrol diri siswa di SMA Negeri 7 Padang dapat dilihat pada tabel berikut ini:

Tabel 1. Distribusi Frekuensu dan Persentase Kontrol diri Siswa

\begin{tabular}{|c|c|c|c|}
\hline Kategori & Interval & $\mathbf{F}$ & $\%$ \\
\hline Sangat Tinggi & $\geq 164$ & 31 & 12,9 \\
\hline Tinggi & $146-163$ & 46 & 19,2 \\
\hline Sedang & $128-145$ & 93 & 38,8 \\
\hline Rendah & $110-127$ & 56 & 23,3 \\
\hline Sangat Rendah & $\leq 109$ & 14 & 5,8 \\
\hline Jumlah & & 240 & 100 \\
\hline
\end{tabular}

Berdasarkan tabel 1, di atas dapat diketahui bahwa secara keseluruhan kontrol diri siiswa berada pada kategori sedang dengan persentase 38,8\%. Disamping itu kategori sangat rendah sebnyak 14 orang $(5,8 \%)$.

\section{Kontrol Perilaku} berikut:

Berdasarkan hasil penelitian, dapat dijelaskan kontrol diri siswa dilihat dari aspek perilaku adalah sebagai

Tabel 2. Distribusi Frekuensi dan Persentase Kontrol Diri Siswa pada Sub Variabel Perilaku $(n=240)$

\begin{tabular}{lcccc}
\hline & Kategori & Interval & F & \% \\
\hline Sangat tinggi & & $\geq 72$ & 43 & 17,9 \\
Tinggi & $62-71$ & 65 & 27,1 \\
Sedang & $53-61$ & 78 & 32,5 \\
Rendah & $43-52$ & 38 & 15,8 \\
Sangat Rendah & & $\leq 42$ & 16 & 6,7 \\
\hline
\end{tabular}

Berdasarkan tabel 2, dapat diketahui pada sub variabel perilaku, sebanyak 43 orang $(17,9 \%)$ berada pada kategori sangat tinggi, 65 orang siswa $(27,1 \%)$ dikategorikan tinggi, 78 orang siswa (32,5\%) dikategorikan sedang, 38 orang siswa $(15,8 \%)$ dikategorikan rendah, dan 16 orang siswa dikategorikan sangat rendah. Berdasarkan pemaparan di atas, secara keseluruhan kontrol diri siswa berada pada kategori sedang. Artinya, sebagian besar siswa dapat mengontrol diri dilihat dari aspek perilaku. 


\section{Kontrol Kognitif} berikut:

Berdasarkan hasil penelitian, dapat dijelaskan kontrol diri siswa dilihat dari aspek kognitif adalah sebagai

Tabel 3. Distribusi Frekuensi dan Persentase Kontrol Diri Siswa pada Sub Variabel Kognitif $(n=240)$

\begin{tabular}{lccc}
\hline \multicolumn{1}{c}{ Kategori } & Interval & f & \% \\
\hline Sangat tinggi & $\geq 55$ & 37 & 15,4 \\
Tinggi & $47-54$ & 76 & 31,7 \\
Sedang & $39-46$ & 94 & 39,2 \\
Rendah & $31-38$ & 29 & 12,1 \\
Sangat Rendah & $\leq 30$ & 4 & 31,7 \\
\hline & & 240 & 100 \\
\hline
\end{tabular}

Berdasarkan tabel 9, dapat diketahui pada sub variabel kontrol kognitif, sebanyak 37 orang siswa $(15,4 \%)$ dikategorikan sangat tinggi, 76 orang siswa (31,7\%) dikategorikan tinggi, 94 orang siswa (39,2\%) dikategorikan sedang, 29 orang siswa $(12,1 \%)$ dikategorikan rendah, dan 4 orang siswa $(12,1 \%)$ berada pada kategori sangat rendah. Hasil temuan ini membuktikan bahwa kontrol diri siswa dilihat dari aspek kognitif berada pada kategori sedang. Artinya, sebagian besar siswa dapat mengontrol diri dilihat dari aspek kognitif.

\section{Kontrol Keputusan}

Berdasarkan hasil penelitian, dapat dijelaskan kontrol diri siswa dilihat dari aspek keputusan adalah sebagai berikut:

Tabel 4. Distribusi Frekuensi dan Persentase Kontrol Diri Siswa pada Sub Variabel Keputusan $(n=240)$

\begin{tabular}{lccc}
\hline \multicolumn{1}{c}{ Kategori } & Interval & F & \% \\
\hline Sangat tinggi & $\geq 40$ & 46 & 19,2 \\
Tinggi & $34-39$ & 68 & 28,3 \\
Sedang & $28-33$ & 68 & 28,3 \\
Rendah & $21-27$ & 48 & 20 \\
Sangat Rendah & $\leq 20$ & 10 & 4,2 \\
\hline
\end{tabular}

Berdasarkan tabel 10, dapat diketahui pada sub variabel kontrol keputusan, sebanyak 46 orang siswa $(19,2 \%)$ pada kategori sangat tinggi, 68 orang siswa $(28,3 \%)$ dikategorikan tinggi, 68 orang siswa $(28,3 \%)$ dikategorikan sedang, 48 orang siswa (20\%) dikategorikan rendah, dan 10 orang siswa dikategorikan sangat rendah. Hasil temuan ini membuktikan bahwa kontrol diri siswa dilihat dari aspek keputusan berada pada kategori sedang. Artinya, sebagian besar siswa dapat mengontrol diri dilihat dari aspek keputusan.

\section{Prestasi Belajar}

Pada variabel prestasi belajar diperoleh dari deskriptif data dapat dilihat pada tabel berikut:

Tabel 5. Distribusi Frekuensi Variabel Prestasi Belajar Siswa

\begin{tabular}{ccc}
\hline Prestasi Belajar Siswa & F & \% \\
\hline $40-45$ & 3 & 1.3 \\
$46-51$ & 9 & 3.8 \\
$52-58$ & 32 & 13.3 \\
$59-61$ & 36 & 15.0 \\
$62-67$ & 64 & 26.7 \\
$68-73$ & 24 & 10.0 \\
$74-79$ & 24 & 10.0 \\
$80-85$ & 40 & 16.7 \\
$86-90$ & 8 & 3.3 \\
\hline Jumlah & $\mathbf{2 4 0}$ & $\mathbf{1 0 0}$ \\
\hline
\end{tabular}


Berdasarkan tabel didapatkan siswa dengan nilai hasil belajar 62-67 yaitu (26,7\%). Berdasarkan hasil penelitian yang dilakukan, terungkap hubungan kontrol diri dengan prestas belajar siswa SMA Negeri 7 Padang, berada pada kategori sedang.

\section{Pengujian Persyaratan Analisis}

Penelitian ini menggunakan rumus statistik parametrik untuk menguji hipotesisnya, yaitu teknik korelasi product moment. Teknik ini baru dapat dilaksanakan apabila telah memenuhi beberapa persyaratan, yaitu; data sampel setiap variabel berdistribusi normal dan garis regresi yang menghubungkan variabel bebas dengan variabel terikat bersifat linear.

\section{Uji Normalitas}

Analisis uji normalitas dalam penelitian ini bertujuan untuk menguji asumsi bahwa distribusi sampel dari data sampel mendekati normalitas populasi. Pengujian normalitas penyebaran skor data dengan menggunakan uji Kolomogorov Smirnov (uji K-S) dengan bantuan program komputer software SPSS versi 20 for windows. Taraf signifikansi yang digunakan sebagai dasar menolak atau menerima keputusan normal/tidaknya suatu distribusi data adalah $\alpha 0,05$.

Tabel 3. Hasil Uji Normalitas Variabel Kontrol Diri (X) dengan Variabel Prestasi Belajar Siswa (Y)

\begin{tabular}{cccc}
\hline \multirow{2}{*}{ Variabel } & \multicolumn{3}{c}{ Kolmogorov-Smirnov } \\
\cline { 2 - 4 } Unstandardized Residual & $\mathbf{K}-\mathbf{S}$ & Asymp. Sig ( 2-tailed & Ket \\
& 0,026 & 0,200 & Normal \\
\hline
\end{tabular}

Berdasarkan hasil perhitungan dengan software SPSS versi 20 for window, diperoleh nilai signifikan $\alpha$ yang dipakai 0,05. Berdasarkan landasan pengambilan keputusan di atas, Hi di terima dan Ho ditolak. Dengan demikian dapat dinyatakan bahwa data dari variabel dalam penelitian ini sebarannya membentuk distribusi normal sehingga hal ini memungkinkan untuk proses analisis selanjutnya.

\section{Uji Homogenitas}

Tabel 4. Hasil Perhitungan Uji Homogenitas Variabel Kontrol Diri dengan Prestasi Belajar Siswa

\begin{tabular}{llrrrr}
\hline Levene Statistic & & df1 & df2 & Sig. \\
& & & & \\
\hline & 0.989 & & 27 & 210 & 0.485 \\
\hline
\end{tabular}

Berdasarkan hasil perhitungan dengan software SPSS versi 20 for windows, diperoleh nilai $\mathrm{r}$ (probability value/critical value) 0,485 lebih besar dari pada tingkat $\alpha$ yang digunakan yaitu 0,05 atau $0,485>0,05$, sehingga Ha diterima dan Ho ditolak. Dengan demikian dapat dinyatakan bahwa skor-skor pada variabel kontrol diri menyebar secara homogen.

\section{Uji Linearitas}

Tabel 5. rangkuman Uji Linearitas varfiabel X terhadap Variabel

\begin{tabular}{ccccc}
\hline Variabel & \multicolumn{4}{c}{ Deviation from Linerity } \\
\cline { 2 - 5 } & Df & F & Sig. & \\
$\mathrm{X}-\mathrm{Y}$ & 74 & & 0.902 & 0.687 \\
\hline
\end{tabular}

Berdasarkan hasil perhitungan dengan software SPSS versi 20 for window, diperoleh skor $\mathrm{r}$ (probabiliry value) sebesar 0,687 sedangkan signifikansi $\alpha$ yang dipakai 0,05. Berdasarkan landasan pengambilan keputusan di atas, Ha diterima dan Ho ditolak sehingga data distribusi kontrol diri (X) dengan prestasi belajar (Y) berpola linear. Kesimpulannya variabel konytrol diri (X) mempunyai pola yang linear dengan prestasi belajar (Y) siswa. 


\section{Uji Hipotesis}

Tujuan penelitian yang ketiga adalah menguji apakah terdapat hubungan antara kontrol diri dengan prestasi belajar siswa. Nilai koefisien korelasi dihitung melalui teknik analisis Product Moment Correlation dengan bantuan aplikasi SPSS 20.00. Hipotesis yang diajukan dalam penelitian ini adalah terdapat hubungan yang positif secara signifikan antara kontrol diri dengan prestasi belajar siswa. Berikut ini hasil analisis korelasi antara kedua variabel.

Tabel 6. Rangkuman Hasil Uji Korelasi Kontrol Diri dengan Prestasi Belajar Siswa

\begin{tabular}{ccccc}
\hline Aspek & N & Rhitung & Sig & Kesimpulan \\
\hline X & 220 & 0,498 & 0,000 & Berkorelasi \\
\hline
\end{tabular}

Tabel 9 di atas terlihat nilai koefisien korelasi (r) antara variabel kontrol diri (X) dengan prestasi belajar siswa (Y), yaitun sebesar 0,498 dengan signifikansi 0,000 yang lebih kecil dari 0,05. Dapat disimpulkan hipotesis $\left(\mathrm{H}_{1}\right)$ yang daijukan dalam penelitian adalah terdapat hubungan yang positif sevcara signifikan antara kontrol diri dengan prestasi belajar siswa berada pada kategori sedang. Besarnya korelasi 0,498 bermakna apabila kontrol diri tinggi,maka prestasi belajar juga tinggi, dan sebaliknya apabila kontrol diri rendah maka prestasi belajar juga rendah.

\section{KESIMPULAN}

Berdasarkan hasil penelitian dan pembahasan yang telah dipaparkan pada Bab IV mengenai hubungan kontrol diri dengan prestasi belajar siswa SMA Negeri 7 Padang, dapat disimpulkan sebagai berikut: 1) Kontrol diri berdasarkan secara keseluruhan berada pada kategori sedang dengan persentase $38,8 \%$,2) Kontrol diri siswa berdasarkan aspek perilaku berada kategori sedang dengan persentase 32,5\%, aspek kognitif sedang dengan persentase $39,2 \%$ dan aspek kontrol keputusan sedang dengan persentase $28,5 \%$.

\section{DAFTAR RUJUKAN}

Astria, L.W. (1990). Pengaruh Perbedaan Jenis Kelamin dan Kontrol Diri terhadap Keputusan pembelian Impulsif. Jurnal Bimbingan dan Konseling. 1(2), 4-5.

Chaplin. (2011). Kamus Lengkap Psikologi. Jakarta: Raja Grafindo Persada.

Barseli, M., Ahmad, R., \& Ifdil, I. (2018). Hubungan stres akademik siswa dengan hasil belajar. Jurnal EDUCATIO: Jurnal Pendidikan Indonesia, 4(1), 40-47.

Barseli, M., \& Ifdil, I. (2017). Konsep Stres Akademik Siswa. Jurnal Konseling dan Pendidikan, 5(3), 143-148.

Ifdil, I., Denich, A. U., \& Ilyas, A. (2017). Hubungan Body Image dengan Kepercayaan Diri Remaja

Putri. Jurnal Kajian Bimbingan dan Konseling, 2(3), 107-113.

Depdiknas. (2003). Undang-undang RI No. 20 Tahun 2003. Tentang Sistem Pendidikan Nasional.

Elani. (2015). Kontrol Diri dengan Perilaku Kenakalan Remaja. Jurnal Psikologi. 1(2), 1-2.

Fitri, E., Zola, N., \& Ifdil, I. (2018). Profil Kepercayaan Diri Remaja serta Faktor-Faktor yang Mempengaruhi. JPPI (Jurnal Penelitian Pendidikan Indonesia), 4(1), 1-5.

Gufron \& Rini. (2011). Teori-Teori Psikologi. Yogyakarta: Ar-Ruzz Media.

Ifdil, I. (2018). Mengembangkan Kesehatan Mental di Lingkungan Keluarga dan Sekolah. Journal of Innovative Counseling: Theory, Practice, and Research, 2(02), 1-9.

Miftakhul. (2017). Tingkat Kontrol Diri Remaja. Jurnal Ilmiah. 3(2), 1-2.

Prayitno \& Amti, E. (2004). Dasar-Dasar Bimbingan dan Konseling. Padang: UNP Press.

Reski, N., Taufik, T., \& Ifdil, I. (2017). Konsep diri dan kedisiplinan belajar siswa. Jurnal EDUCATIO: Jurnal Pendidikan Indonesia, 3(2), 85-91.

Suryabrata. (2006). Proses Belajar Mengajar di Perguruan Tinggi. Yogyakarta: Andi Offest.

Syah, M. (2011). Psikologi Remaja. Yogyakarta: PT Tiara Wacana.

Wardi, R., \& Ifdil, I. (2016). Stress Conditions in Students Completing Thesis. GUIDENA: Jurnal Ilmu Pendidikan, Psikologi, Bimbingan dan Konseling, 6(2), 190-194.

Zola, N., Fadli, R. P., \& Ifdil, I. (2018). Chromotherapy to reducing stress. 